\title{
APRENDIZAGEM DO PORTUGUÊS POR IMIGRANTES HAITIANOS: PERCEPÇÃO DAS CONSOANTES LIQUIDAS /L/ E / $/$ /
}

\author{
Susiele Machry da Silva* \\ Universidade Tecnológica Federal do Paraná \\ Pato Branco, Paraná, BR
}

\section{Resumo}

Este artigo versa sobre a aquisição do português brasileiro como Língua Adicional por imigrantes haitianos, mais precisamente no que tange à percepção das consoantes líquidas /l/ e / $/$ / na posição intervocálica, em formas como pala, mala, Sara. Participaram do estudo 14 imigrantes haitianos residentes, no momento da pesquisa, na cidade de Pato Branco-PR, com média de idade de 30,07 (DP =4,98), todos do sexo masculino. A discussão dos dados é pautada nos pressupostos teóricos da Aquisição Fonológica de L2 (FLEGE, 1995; BEST; TYLER, 2007) e os resultados mostram tendência ao processo de assimilação, ou seja, sem a categorização separada de /l/ e $/ \mathrm{r} /$. Verifica-se ainda um efeito positivo do tempo de curso e do fato de o informante residir no Brasil com sua família haitiana, com melhor desempenho para aqueles que frequentam curso por mais tempo e residem no país com sua família.

Palavras-chave: Língua Adicional; Imigrantes Haitianos; Percepção.

\section{PORTUGUESE LANGUAGE LEARNING BY HAITIAN IMMIGRANTS: THE PERCEPTION OF THE LIQUID CONSONANTS /L/ AND / $/$ /}

\begin{abstract}
This paper deals with the acquisition of Brazilian Portuguese as an additional language by Haitian immigrants, more precisely with regard to the perception of liquid consonants /l/ and / $/$ in intervocalic context, as in pala, mala, and Sara. Fourteen Haitian immigrant men with average ages of 30,07 $(\mathrm{SD}=4,98)$ who were living in Pato Branco/PR (Brazil) participated in the study. The discussion is based on theoretical assumptions of L2 Phonological Acquisition (FLEGE, 1995; BEST; TYLER, 2007) and results revealed a tendency to the assimilation process, which means that $/ 1 /$ and $/ \mathrm{r} /$ are categorized together. Besides, the participants who attended the language classes the longest and lived in Brazil with their Haitian families showed a positive effect in perceiving the liquids.
\end{abstract}

Key-words: Additional language; Haitian immigrants; Perception.

\section{Introdução}

No contexto atual, o Brasil tem sido a principal porta de entrada de imigrantes haitianos, que têm se instalado em diversas regiões do país. Provenientes de diferentes cidades/departamentos do Haiti, esse grupo de imigrantes tem buscado no Brasil um refúgio com oportunidades de emprego e consequente geração de renda para o sustento de suas famílias. Os motivos pelos quais os haitianos procuram o Brasil, e também as condições que permeiam tanto suas vindas quanto suas estadas aqui, fazem deste um grupo bastante específico. Com a necessidade de rapidamente se engajar no mercado de trabalho brasileiro, haitianos sentem a urgente demanda de aprender o idioma oficial do país, muitas vezes sem nenhum tipo de contato anterior ou instrução formal.

Torna-se, frente a isso, evidente a necessidade de oferta da língua portuguesa aos imigrantes haitianos

“Professora Adjunta da Universidade Tecnológica Federal do Paraná, Pato Branco, Paraná - BR. Doutora e Mestre em Letras pela Pontifícia Universidade Católica do Rio Grande do Sul. Endereço de e-mail: susiele.machry@gmail.com 
que aqui chegam. Embora seja o Brasil caracterizado como um país plurilíngue, marcado pela multiplicidade de contatos e a diversidade linguística (ALTENHOFEN; OLIVEIRA, 2011; FERRAZ, 2007), a constante necessidade de uso do português brasileiro (doravante PB), língua nesse contexto majoritária nas interações sociais, faz com que esses imigrantes procurem adaptar-se de forma emergencial aos usos linguísticos predominantes no país. A inserção social, seja por trabalho, estudo, religião, ou por motivos outros, requer o uso da língua portuguesa por parte do imigrante nas suas situações cotidianas. Em outras palavras, seguindo a perspectiva apresentada em Ponso (2003), pode-se entender a pressão social como o principal fator externo a exigir do imigrante o conhecimento da língua dominante.

No que tange aos imigrantes haitianos, há ainda outras questões que precisam ser observadas ao se realizarem estudos que se voltam para a aprendizagem de outras línguas, no caso desta pesquisa, o português. $\mathrm{O}$ crioulo haitiano pode ser caracterizado como uma língua mista, no sentido de ser formada por mais de uma base; ademais, considera-se o fato de que os imigrantes haitianos, por serem oriundos de diferentes regiões do Haiti, falam, ou pelo menos têm contato, com mais de uma língua, incluindo o francês, o espanhol e o inglês.

Além dessas características, o grupo é bastante específico quanto aos propósitos emergentes de comunicação, em que o contato com o português, na maioria das vezes, acontece somente no meio social ou pela oferta de cursos gratuitos, que tem sido uma iniciativa recorrente. Não obstante, pela urgente necessidade, os cursos muitas vezes carecem de material mais direcionado às características do grupo e do foco em habilidades específicas da língua alvo. ${ }^{1}$ Conhecer as necessidades desses imigrantes e contribuir com o aprimoramento de suas habilidades linguísticas tornase uma tarefa gratificante e necessária.

A partir do exposto e considerando a demanda cada vez mais emergente de "recepção linguística" aos imigrantes haitianos em Língua Adicional, ${ }^{2}$ este estudo tem foco nos aspectos fonéticolfonológicos, no que tange à percepção do contraste entre as líquidas do português brasileiro, /l/ e / / / Justifica-se a escolha do tema pelo fato de ainda ser restrito o número de estudos explorando a aquisição do português pelos haitianos, mais precisamente nas áreas que englobam Fonética e Fonologia. A escolha por trabalhar com as consoantes líquidas partiu dos apontamentos realizados por estudos preliminares (MARTINS, 2013; SANTOS; BURGEILE, 2015; SILVA, 2015; PIMENTEL; COTINGUIBA; RIBEIRO, 2016), bem como do diagnóstico realizado a partir dos cursos de extensão direcionados aos haitianos na cidade de Pato Branco- PR.

A proposta deste artigo concentra-se na habilidade dos imigrantes haitianos em perceberem os sons do português, mais precisamente os segmentos /l/ e / $\mathrm{r} /$, como contrativos, ou seja, como categorias fonológicas distintas. Nesse caso, a hipótese é de que a dificuldade dos aprendizes no reconhecimento, quando existente, decorre do fato de o segmento / $\mathrm{r} /$, não presente no crioulo haitiano, por similaridade, ser percebido como /1/.

A discussão é pautada nos pressupostos teóricos que sustentam a aprendizagem fonológica em Segunda Língua (FLEGE, 1995; BEST; TYLER, 2007). Parte-se do entendimento de que a pronúncia em língua não nativa, frequentemente marcada pelo sotaque estrangeiro, principalmente para os que adquirem a língua na fase adulta (como é o caso dos informantes deste estudo), pode decorrer de uma percepção inadequada dos sons da língua alvo (FLEGE, 1995; STRANGE; SHAFER, 2008). Embora nem sempre se confirme uma correlação positiva entre percepção e produção (BETTONI-TECHIO; RAUBER; KOERICH, 2007; HATTORI; IVERSON, 2010; PEPERKAMP; BOUCHON, 2011), entende-se que, quando não há um treinamento articulatório mais direcionado, muitas das dificuldades de pronúncia podem ser decorrentes da dificuldade de percepção/compreensão dos sons não nativos.

Diante dessa possibilidade, justifica-se a importância de direcionar a proposta para o estudo da habilidade perceptual dos aprendizes, com vistas a diagnosticar possíveis dificuldades na compreensão dos segmentos não nativos, mostrando evidências da categorização não separada dos segmentos da língua não nativa em relação aos da língua nativa.

Mensura-se o grau de dificuldade de adequação aos padrões fonológicos da língua alvo com base na similaridade/diferença dos sons a serem adquiridos na 
língua não nativa com os sons já existentes na língua nativa do aprendiz. Quanto mais semelhantes forem os sons da língua não nativa com os sons da língua materna, maior é a probabilidade de o aprendiz associá-los a uma categoria fonológica já existente na sua língua. Ao contrário, quando os sons da língua não nativa são notavelmente distintos da língua nativa, maior é a probabilidade de, por um processo de dissimilação, os sons serem alocados em categorias distintas, ou seja, reconhecidos como novos sons (FLEGE, 1995; BEST; TYLER, 2007).

Ao explorar aspectos que compreendem Fonética e Fonologia, o estudo pode vir a contribuir para a elaboração de material didático mais direcionado às reais necessidades dos imigrantes haitianos, contribuindo para um processo de desenvolvimento da fala não nativa mais abrangente. Nesse sentido, o artigo proposto busca, com apoio da literatura de Aquisição Fonológica em L2 (FLEGE, 1995; BEST; TYLER, 2007; STRANGE; SHAFER, 2008), apresentar um diagnóstico do grupo quanto à percepção de segmentos que têm se mostrado de maior dificuldade para os haitianos. O desempenho do grupo será mensurado com base em fatores individuais e de convívio social, tais como idade, tempo de residência no país, situação de sua residência no Brasil, assim como o tempo que frequenta curso de português, e o tempo de uso e exposição à língua em diferentes situações cotidianas.

\section{Crioulo Haitiano: origem e aspectos relaciona- dos à fonologia da língua}

O crioulo haitiano é hoje a primeira língua oficial da República do Haiti. Embora boa parte da população utilize também o Francês, língua com status de maior prestígio (RODRIGUES, 2008; SANTOS; BURGEILE, 2015), o crioulo constitui a língua materna de grande parte da ilha. Além do crioulo e do francês, boa parte dos haitianos diz falar e compreender também o espanhol e o inglês. São observadas ainda situações de diferenças dialetais; isto é, a depender da localização geográfica dos departamentos ou estados de origem dos imigrantes, estão presentes na formação linguística dos haitianos outros dialetos do crioulo haitiano. As pes- quisas na área mencionam pelo menos três principais dialetos no Haiti: o dialeto do sul, o dialeto do norte e o dialeto do oeste, que inclui a capital. Diferenças dialetais se espalham, assim, pelas regiões da ilha (BONENFANT, 2011).

De acordo com Pimentel, Cotinguiba e Ribeiro (2016, p. 32) "as origens do crioulo haitiano podem ser levantadas, mas seu início é uma incógnita e, provavelmente, insondável". O crioulo foi se formando como uma língua de contatos dos escravos de origem africana com os colonos franceses e constitui-se uma língua social, conforme enfatizam os autores, fruto da necessidade de interação comunicativa. O francês, língua base, era a língua do superstrato, dominada pela elite e pelos colonizadores, enquanto o crioulo haitiano configurava-se como a língua dos então escravos (CAISSE, 2012). Por sua formação, Bonenfant (2011, p. 28) salienta que o crioulo é frequentemente associado, de forma negativa, por sua relação com pidgins, sendo por vezes interpretado como uma forma simplificada de outras línguas.

Na mesma linha, Spears (2010) ressalta que "algumas pessoas podem pensar equivocadamente que $o$ crioulo é uma língua simples ou primitiva em comparação com línguas como o francês, digamos, por não ter sufixos de inflexões verbais para tempo pessoa e número"3 (p. 3). No entanto, o autor ressalta que o crioulo tem seu próprio modo de expressar esses conceitos e não se pode usar a gramática do francês como um modelo para o entendimento da gramática do crioulo. Trata-se, portanto, de duas línguas diferentes.

Tendo o francês o status de maior prestígio em relação ao crioulo haitiano (RODRIGUES, 2008), sua utilização também predomina em muitos lares, principalmente das classes com maior poder aquisitivo, como segunda língua em algumas escolas do Haiti e até mesmo, como língua básica de ensino em outras escolas, principalmente as localizadas na ou próximas à capital do país. $\mathrm{O}$ francês, por seu status, portanto, continua a ocupar uma posição importante entre os haitianos. Ao lado do francês está o inglês, língua também utilizada em boa parte das escolas e em algumas relações comerciais.

Como língua prevalentemente falada desde sua origem, o crioulo haitiano procura representar seu 
sistema gráfico por sua fonologia. Segundo Rodrigues (2008, p. 97), cabe ressaltar, no entanto, que "o alfabeto atualmente utilizado está longe de representar um consenso", estando passível de modificações. O francês, segundo o autor, continua a ser a língua utilizada em muitos meios de comunicação escrita, de divulgação comercial e sinalização de trânsito, a exemplo.

Pelo difícil levantamento da origem, bem como pela formação mista, com traços do francês e das Línguas Africanas, torna-se complexo o levantamento das características do crioulo haitiano, de sua gramática
RODRIGUES, 2008), características de pronúncia mais semelhantes às Línguas Africanas do que ao francês.

O sistema fonológico do crioulo haitiano apresenta um número aproximado de 22 consoantes (BEAUBRUN, 2004). Seu sistema fonológico é em boa parte semelhante ao do português, conforme o Quadro 1, que representa, por ponto e modo de articulação, a classificação das consoantes em comparação com o sistema do PB.

Quadro 1 - Sistema Fonológico -Crioulo Haitiano versus Português Brasileiro

\begin{tabular}{|l|l|l|l|l|l|l|l|}
\hline & Bilabial & Labiodental & Inderdental & Alveolar & Pal. Alveolar & Palatal & Velar \\
\hline Obstruintes & $\mathrm{p} \mathrm{b}$ & & & $\mathrm{t} \mathrm{d}$ & & & $\mathrm{k} \mathrm{g}$ \\
\hline Fricativas & & $\mathrm{f} \mathrm{v}$ & & $\mathrm{s} \mathrm{z}$ & $\mathrm{S} 3$ & & $\mathrm{X}^{*} \mathrm{\gamma}^{* *}$ \\
\hline Africadas & & & & & $\mathrm{t}^{* * *} \mathrm{~d}^{* * *}$ & & \\
\hline Nasais & $\mathrm{m}$ & & & $\mathrm{n}$ & & $\mathrm{n}$ & \\
\hline Tepe & & & & $\mathrm{r}^{*}$ & & & \\
\hline Lateral & & & & $\mathrm{l}$ & & $\kappa$ & \\
\hline Vibrante & & & & $\mathrm{r}^{*}$ & & & \\
\hline Glide & $\mathrm{w} \mathrm{u}^{* *}$ & & & & $\mathrm{~J}$ & & \\
\hline
\end{tabular}

e de sua fonologia. Ainda há carência de pesquisas sobre a fonologia do crioulo haitiano, e as poucas pesquisas que existem envolvem opiniões diferenciadas acerca da classificação dos fonemas. Além disso, conforme Caisse (2012), há poucos registros escritos no crioulo haitiano, que por muitos anos prevaleceu como língua falada, sem uma ortografia unificada. De acordo com Rodrigues (2008), boa parte do léxico do crioulo deriva ou vem diretamente do francês, mas o crioulo difere consideravelmente desta língua na sintaxe, na morfologia e na semântica, mantendo ainda traços de invariabilidade e nasalização não característicos do francês, estando nesses aspectos o crioulo mais próximo das Línguas Africanas.

O crioulo é considerado atualmente uma língua independente, tendo como língua de base o francês, em maior parte de sua origem, mas com consideráveis características fonológicas, morfológicas e sintáticas das línguas da África Ocidental (BONENFANT, 2011; HALL, 1971 apud BEAUBRUN, 2004). Ou seja, o crioulo preserva, segundo estudos (MARTINS, 2013;
Fonte: com base em Beaubrun (2004, p. 46) - CH e Mattoso Câmara (2009) - PB

No quadro, as consoantes não marcadas com asterisco $\left({ }^{*},{ }^{* *}\right.$ ou $\left.{ }^{* * *}\right)$ estão presentes nas duas línguas; as consoantes marcadas por dois asteriscos $\left({ }^{* *}\right)$ estão presentes no crioulo haitiano apenas; por sua vez, as consoantes marcadas por um único asterisco ${ }^{*}$ ) fazem parte somente do sistema consonantal do PB. Ainda faz-se referência às consoantes $\mathrm{t} \int \mathrm{e} \mathrm{d} 3$, marcadas como $\left.{ }^{* * *}\right)$, que no $\mathrm{PB}$ constituem alofones (CRISTÓFARO SILVA, 2005), uma vez que não apresentam na língua valor contrastivo, estando presentes somente diante de "i", como resultado do processo de palatalização (BISOL, 2010). Vale a ressalva de que o sistema consonantal do $\mathrm{PB}$, por sua variabilidade, pode apresentar diferentes pronúncias de acordo com a variedade dialetal. Os fonemas / $1 /$ e $/ \mathrm{r} /$, a exemplo, de acordo com a posição na sílaba, são na língua suscetíveis de variação, podendo apresentar outras pronúncias, a depender da variedade dialetal (CRISTÓFARO SILVA, 2005; MONARETTO, 2009). 
$\mathrm{O}$ número e a classificação das consoantes do crioulo haitiano ainda encontram controvérsias entre os estudos sobre a língua. Alguns autores classificam, por exemplo, o /r/ como uma fricativa velar / $/ \mathrm{y} /$ (CADELY, 2004), enquanto outros o classificam como uma aproximante velar (VERNET, 1980). Não há registro no crioulo haitiano do contraste entre a vibrante /r/ e o tepe / $\mathrm{r} /$, contrastivo no português brasileiro (caro - carro), assim como o contraste que se forma entre o tepe / $\mathrm{r} /$ e o /1/ (cala - cara). Os registros decorrentes do trabalho em aula e os resultados de estudos sobre a língua apontam que a substituição na pronúncia dos fonemas $/ 1 / \mathrm{e} / \mathrm{r} /$, objeto de estudo deste artigo, tende a ser frequente entre o grupo (MARTINS, 2013), com registros de trocas de amarelo por amalelo, por exemplo. Além disso, ocorrem outros fenômenos como a supressão de fonemas (ex.: telefone - telefon) e a troca da posição no acento em proparoxítonas ('onibus - oni'bus). ${ }^{4}$

Embora a líquida vibrante $/ r /$ também não esteja presente no crioulo haitiano, na observação prévia e nos pilotos realizados por este estudo, a dificuldade de produção do [r], vibrante, em casos como carro - carrinho, não tende a ser recorrente, acontecendo apenas em casos isolados. Tampouco há registro da dificuldade de diferenciação do contraste entre a vibrante $/ \mathrm{r}$ / e o tepe /r/ (ex.: caro - carro). Tal fato pode ser explicado pela própria característica de formação da língua, com diferentes bases, e das características do grupo, havendo conhecimento de outros idiomas.

O grupo de informantes que faz parte deste estudo, conforme será discutido no método apresentado na próxima seção, é proveniente de diferentes regiões do Haiti, mas todos possuem como língua nativa o crioulo haitiano, informando, terem apenas conhecimento do francês, com alguns casos que apresentam também conhecimento do inglês e do espanhol.

\section{Metodologia}

O estudo foi desenvolvido a partir da coleta de dados de percepção com imigrantes haitianos domiciliados no Brasil. Para participar da pesquisa o informante deveria estar residindo na cidade de Pato Branco - PR. Ao todo foram selecionados 14 imigrantes do sexo masculino, com idade entre 18 e 50 anos, média de idade 30,07 ( $\mathrm{DP}=4,98)$. A inclusão de informantes somente do sexo masculino, assim como com a idade de até 50 anos, deve-se ao propósito de adequar a pesquisa às características do grupo que, em sua maioria, é constituído por adultos jovens do sexo masculino. $\mathrm{O}$ tempo de residência desses imigrantes no Brasil compreende um período entre quatro meses e dois anos. Ao serem contados e informados sobre os objetivos da pesquisa, os informantes foram convidados a assinar um Termo de Consentimento Livre e Esclarecido. ${ }^{5}$

No primeiro contato, com os participantes que aceitaram participar da pesquisa, foi aplicado um questionário que buscou explorar as características do grupo. Nesse questionário, além de questões individuais, foram coletadas informações dos participantes sobre suas condições de exposição, a partir de indagações com aspectos simples: se faz uso da internet em seu cotidiano; as condições em que vive no Brasil (quem são seus companheiros de residência); se trabalha e o tipo de trabalho que realiza; se usa o português no trabalho; se costuma interagir a maior parte do tempo em português ou em crioulo; se costuma assistir televisão ou ouvir rádio em português. No caso dos fatores de exposição, as informações foram consideradas a partir do número de horas, estabelecendo um tempo de 0 até 06 horas diárias para cada atividade. $\mathrm{O}$ questionário foi preenchido com o auxílio da pesquisadora e de um monitor que assessorou na escrita e na compreensão de todas as perguntas. Realizou-se, primeiro, a pergunta oralmente, a exemplo de: Você assiste televisão em português? Em caso de resposta positiva, se questionava aproximadamente quantas horas. Assim sucessivamente, procurando ao máximo minimizar os efeitos da compreensão da língua e a consequente atribuição de respostas aleatórias.

Sobre a região de origem, os dados coletados junto ao grupo pesquisado revelam que grande parte dos haitianos é proveniente de diferentes departamentos/estados do Haiti, sendo a maioria dos espaços geográficos mais atingidos pelo terremoto de 2010, incluindo a capital, Porto Príncipe. Grande parte desses imigrantes relata viver já no Haiti em condições de vulnerabilidade social. Outros manifestam ter realizado cursos de formação pro- 
fissional ou de graduação no Haiti, com conhecimento nas diferentes áreas profissionais. A Figura 1 representa o mapa e as regiões do Haiti, sinalizando os departamentos de onde são provenientes os participantes deste estudo, conforme informações coletadas com o grupo.

Figura 1 - Mapa das regiões de origem dos haitianos

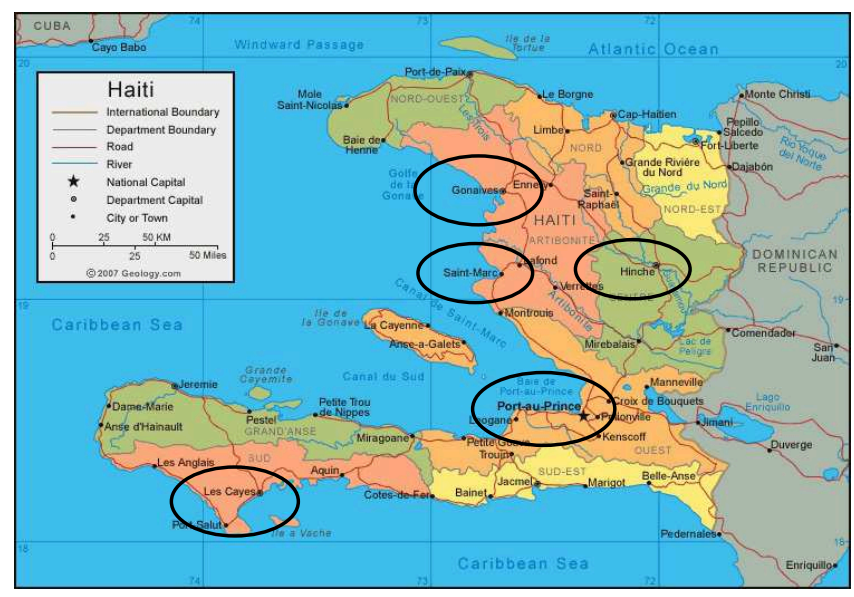

Fonte: Mapas do Haiti/geografia do Haiti

A maioria dos informantes revela ser proveniente das regiões de Les Cayes, Port-au-Prince (capital), Hinche, Gonaïves e Anso-à-Galets. Todos relatam ter o francês como segunda língua e apenas dois informantes provenientes das regiões Gonaïves e Anse-à-Galets dizem ter o conhecimento do espanhol. Quatro dos informantes informaram ter conhecimento básico do inglês, tendo tido contato com a língua nas escolas primárias.

Pelas características do grupo e dada a dificuldade relacionada tanto ao uso do computador, como também com a compreensão das tarefas, antes da aplicação dos testes deste estudo foram realizados momentos de treinamento. Nesses treinamentos, realizados no laboratório de informática da Universidade Tecnológica Federal do Paraná, os informantes realizavam os mesmos tipos de testes incluídos no estudo: discriminação e identificação, não obstante, contemplando outros tipos de segmentos e palavras (ex.: pata - bata; mata, lata, tapa, bicicleta), não aqueles que são alvos deste estudo. Na oportunidade, foram realizadas também tarefas para identificar a posição da consoante na sílaba, se no início, segunda ou terceira sílaba, procurando assim minimizar dificuldades na compreensão da tarefa a ser proposta. Durante o treinamento, os informantes rece- biam instruções e tinham a liberdade de tentar quantas vezes desejassem desenvolver a tarefa.

A instrução inicial com teste também serviu para avaliar a qualidade dos estímulos, que foram previamente gravados por três locutores falantes nativos do português brasileiro, sendo dois do sexo feminino e um do sexo masculino. Na gravação utilizou-se gravador digital Zoom H4N com a configuração da taxa de amostragem para $22.050 \mathrm{HZ}$ e 16bits. As palavras a serem gravadas foram inseridas em uma frase veículo do tipo "Digo X com cuidado", alocando sempre a palavra alvo na posição de X. Após a gravação, realizada em sala silenciosa, as palavras a serem utilizadas como estímulos foram segmentadas, transferidas para o computador e editadas para a normalização da intensidade de voz dos locutores.

Os dois testes, discriminação do tipo AX e identificação, foram elaborados com o auxílio do software TP (RAUBER et al., 2012). Para o teste de discriminação foram selecionados vinte (20) pares de palavras com o contraste /l/ - / $/$ / em posição intervocálica, preferencialmente pares mínimos do tipo caro - calo, pula pura, falo - faro. Além dos 20 pares contrastivos, foram incluídos no teste oito pares não contrastivos, do tipo bula - pula, pera - cera, mínimos ou análogos, e outros seis pares de palavras distratoras, nesse caso, com a presença de outros segmentos. Cada par de palavra foi repetido duas vezes na aplicação do teste, totalizando sessenta e oito estímulos. O teste foi configurado de forma que, ao ouvir um par de palavras, com um intervalo de silêncio de 1,2 segundos entre uma e outra palavra, o informante deveria identificar se a consoante em início de sílaba era semelhante nas duas palavras ou diferente. Na tela do experimento apareciam apenas as opções "semelhante" e "diferente". Salienta-se que todas as palavras incluídas no teste continham duas sílabas e sempre a consoante alvo ocupava o onset da segunda sílaba da palavra (ex.: pala - para).

O teste de identificação foi composto por quarenta (40) palavras, sendo vinte (20) com a líquida /1/ (ex.: sala, solo, pala, pila) e vinte com a líquida / $/$ / (ex.: pira, para, pura). Nesse caso, foram incluídas outras doze palavras distratoras com outros segmentos (ex.: pata, dado). O informante, ao ouvir uma palavra de cada vez, deveria marcar a consoante com o som mais pró- 
ximo ao ouvido na pronúncia da consoante inicial da segunda sílaba da palavra. Nesse caso, a tela do teste apresentada aos informantes continha seis consoantes, sendo as duas que são objetos de análise $(/ 1 /$ e $/ r /$ ) e as demais correspondentes às palavras distratoras $(/ \mathrm{p} /, / \mathrm{t} /$, $/ \mathrm{s} /, / \mathrm{d} / \mathrm{)}$. Da mesma forma que o teste anterior, o teste de identificação foi constituído por palavras dissílabas, com a consoante alvo ocupando a posição de onset da segunda sílaba. O total para o teste foi de cento e quatro (104) estímulos apresentados, considerando uma repetição para cada estímulo.

$\mathrm{Na}$ aplicação de ambos os testes, o informante tinha a opção de repetir o áudio do estímulo por uma única vez, assim como utilizar o botão "ops", que permitia voltar à tela anterior e responder novamente, caso sentisse equívoco em sua resposta. Justifica-se a escolha por liberar o uso do botão "ops" pelo fato de se ter observado a dificuldade dos informantes na realização dos testes de treinamento inicial. Nas instruções que eram dadas no treinamento, chamou-se a atenção dos informantes tanto para a oportunidade de ouvir os estímulos por uma segunda vez, quanto de voltar, caso percebesse equívoco em sua resposta anterior. Por questões também relacionadas à dificuldade dos informantes com o próprio computador, não se mediu o tempo de resposta e todos os informantes realizaram individualmente as tarefas, dentro do seu tempo. Na realização dos testes os informantes utilizaram um computador portátil, disponibilizado pela pesquisadora, e fone de ouvido, com o volume ajustado individualmente.

Para o levantamento dos dados foram considerados no teste de discriminação somente os pares contrastivos, resposta para os estímulos diferentes, os quais eram objeto de análise. Os pares iguais (ex.: bula - pula), também incluídos no teste, serviram como um controle do experimento, evitando respostas tendenciosas, a exemplo, de o informante marcar a opção diferente para todos os pares ou mesmo de perceber o propósito da tarefa. O levantamento inicial contabilizou o número de acertos para cada teste em termos percentuais, considerando as duas respostas dadas pelo informante. Os dados foram lançados no SPSS, considerando o resultado de média percentual obtida por cada informante, em cada tipo de teste.
$\mathrm{Na}$ análise dos dados foram incluídas variáveis relacionadas ao indivíduo, tais como tempo de residência (em meses), tempo de curso na UTFPR (em meses) e com quem vive no Brasil (sozinho, com amigos brasileiros ou com companheiros de seu país). O tempo de curso foi observado a partir da indicação de que todos os haitianos estão inseridos em cursos de idiomas na cidade de Pato Branco, por meio de iniciativas religiosas ou de cursos de extensão. Normalmente, o ingresso nos cursos se dá nos primeiros meses da chegada do imigrante no Brasil e compreende, no caso dos participantes deste estudo, um tempo entre 02 meses e 18 meses. Ressalta-se que todos os sujeitos envolvidos na pesquisa são adultos e não tiveram contato com o português antes de suas vindas para o Brasil, fato que levou a desconsiderar qualquer interferência da idade de aquisição ou idade do primeiro contato com o idioma.

Além dessas variáveis relacionadas ao indivíduo, foram incluídas variáveis relacionadas ao tempo de uso e de exposição ao $\mathrm{PB}$, nesse caso, divididas de acordo com o tipo de atividade em dois grupos: a) exposição à fala - tempo estimado em que o informante usa o Português na fala (interação com amigos, uso do português no trabalho, entre outros; b) exposição à escuta - tempo que o informante revela ficar exposto em situações de áudio em Português (ouvir rádio, música, televisão, entre outros). Essas informações foram levantadas por meio do questionário aplicado aos informantes, a partir da contabilização das horas informadas nas diferentes atividades (ex.: assistir televisão, ouvir música, falar com colegas de trabalho, falar com amigos, entre outras) e a posterior conversão dos valores em percentuais.

\section{Descrição e discussão dos dados}

O levantamento dos dados para a descrição e análise, conforme o exposto na seção anterior, foi realizado com o auxílio do SPSS. Para o teste de discriminação buscou-se verificar a habilidade dos aprendizes em diferenciar o contraste /l/ - / $/$ / em pares de palavras (ex.: pira - pila). A hipótese é de que, pelo fato de a consoante liquida $/ r /$ não estar presente na língua nativa dos aprendizes, o crioulo haitiano, há tendência de ocorrer o processo de assimilação; ou seja, sugere-se 
que os informantes tendem a não perceber a distinção entre os segmentos /1/ e / / (FLEGE, 1995; BEST; TYLER, 2007). Não obstante, o desempenho dos aprendizes deve estar associado a questões individuais, incluindo o tempo de exposição e de uso da língua alvo.

$\mathrm{Na}$ análise foram considerados somente os pares contrastivos, isto é, aqueles em que as consoantes iniciais da segunda sílaba eram diferentes. No teste de identificação, os indivíduos foram testados quanto a sua habilidade para identificar tanto /l/ quanto / $/$ / em posição de onset da segunda sílaba. A tabela 1, a seguir, apresenta os resultados do grupo, considerando a média percentual obtida em cada teste.

Tabela 1 - Resultado dos testes de percepção

\begin{tabular}{lllll}
\hline Tipo de teste & $\begin{array}{l}\text { Média } \\
\text { do } \\
\text { grupo }\end{array}$ & $\begin{array}{l}\text { Pontuação } \\
\text { mínima } \\
\text { (grupo) }\end{array}$ & $\begin{array}{l}\text { Pontuação } \\
\text { máxima } \\
\text { (grupo) }\end{array}$ & DP \\
\hline $\begin{array}{l}\text { Teste de } \\
\text { discriminação }\end{array}$ & $\mathbf{4 1 , 8 4}$ & 10,00 & 85,00 & 26,66 \\
\hline Identificação /1/ & $\mathbf{5 3 , 8 8}$ & 20,83 & 88,10 & 16,75 \\
\hline Identificação /f/ & $\mathbf{4 9 , 6 5}$ & 11,90 & 80,95 & 20,31
\end{tabular}

Fonte: Elaboração da autora

De acordo com os resultados expressos na tabela anterior, a média do grupo para o teste de discriminação AX foi de 41,84 (DP = 26,66). No teste de identificação observa-se a média de 53,88 (DP = 16,75) para /1/ e de 49,65 para / $/$ / $(D P=20,31)$. Por estes resultados, verifica-se que há melhor desempenho dos aprendizes na habilidade de identificação dos segmentos em relação à habilidade de discriminação dos pares contrastivos. Esse resultado sugere possível sensibilidade dos aprendizes ao detalhe fonético, mas sem haver ainda a dissimilação dos dois fonemas como categorias independentes (BEST; TYLER, 2007; ANTONIOU, TYLER, BEST, 2012). A identificação de /l/ $(53,88)$ e a identificação de /r/ $(49,65)$ mostram resultados muito próximos, sem diferença entre as médias, conforme o teste $T$ para amostras emparelhadas $(\mathrm{t}(13)=0,485, \mathrm{p}=636){ }^{6}$

$\mathrm{O}$ fato de os aprendizes apresentarem dificuldade na tarefa de discriminação do contraste e valores próximos para a identificação dos dois segmentos, /l/ e /r/, incluindo /1/, corrobora a hipótese de que os aprendizes não separam ainda completamente as duas categorias, com tendência a confundir e fazer a substituição do tepe / $\mathrm{r} /$ do PB pelo som existente na sua língua, o segmento /1/. Nesse caso, seguindo a proposta de Flege (1995) e Best e Tyler (2007), na percepção dos aprendizes as duas categorias fonológicas tendem a se sobrepor, não havendo a formação de categorias independentes para cada som, resultando em um processo de equivalência entre o / / presente também na LM e o / $/$ / presente apenas na língua alvo.

Nota-se que os resultados não se aplicam de forma categórica a todos os indivíduos. $\mathrm{O}$ alto desvio padrão e os valores em média máxima, de 85,00 para o teste de discriminação e de 88,10 para o teste de identificação, sugerem que alguns sujeitos apresentam habilidade para o reconhecimento dos sons e suas diferenças. Nesse sentido, fatores individuais tais como o tempo de residência do aprendiz no Brasil, tempo que está frequentando curso, uso e exposição à língua alvo, pela hipótese de que parte este estudo, podem explicar possíveis diferenças de comportamento entre os informantes que compõem a amostra. Nesse caso, tratou-se de realizar a análise a partir das observações desses correlatos.

O tempo de residência no Brasil dos sujeitos que participaram da pesquisa varia em um mínimo de quatro meses até o máximo de dois anos. Ao testar a correlação da variável com o desempenho na discriminação ( $\mathrm{rs}=, 147, \mathrm{p}>0,05)$ do contraste e na identificação de /l/ $(r=, 273, p>0,05) e / r /(r=, 030, p>0,05)$, observouse, em ambas as situações, uma associação positiva, mas não significativa. Tal resultado revela não haver, pelo menos de forma direta, influência do Tempo de Residência no desempenho dos informantes na percepção.

A atuação da variável Tempo de Residência na aquisição de Segunda Língua por imigrantes adultos, em alguns casos não tende a apresentar efeito, uma vez que não há, normalmente, progresso no desempenho com o aumento dos anos de residência (AOYAMA et al, 2008; OH et al, 2011). A variável tende a apresentar efeito quando está atrelada à alta exposição; nesse caso, há possibilidade de os indivíduos apresentarem uma melhora nas habilidades de perceber e produzir 
os sons da língua alvo com o decorrer do tempo, se estes tiverem acesso ao input de qualidade (FLEGE; LIU, 2001). O progresso observado, especialmente dos aprendizes de uma segunda língua em imersão no contexto da L2, revela haver uma associação positiva entre desempenho na L2 e condições de acesso ao input adequado.

A exposição à língua alvo, neste estudo, conforme descrito na seção metodológica, foi medida com base em questões relacionadas a atividades de fala e escuta da língua em situações cotidianas. Com base na média percentual de acordo com as horas de exposição relatadas pelos informantes, procedeu-se à divisão de dois grupos, a saber: Grupo A - exposição cotidiana à fala e escuta com percentual inferior a 50\% (inferior a 03 horas por dia); Grupo B - exposição cotidiana à fala e escuta com percentual superior a 50\% (superior a 03 horas por dia). O Gráfico 1 apresenta a média obtida para cada grupo na tarefa de discriminação.

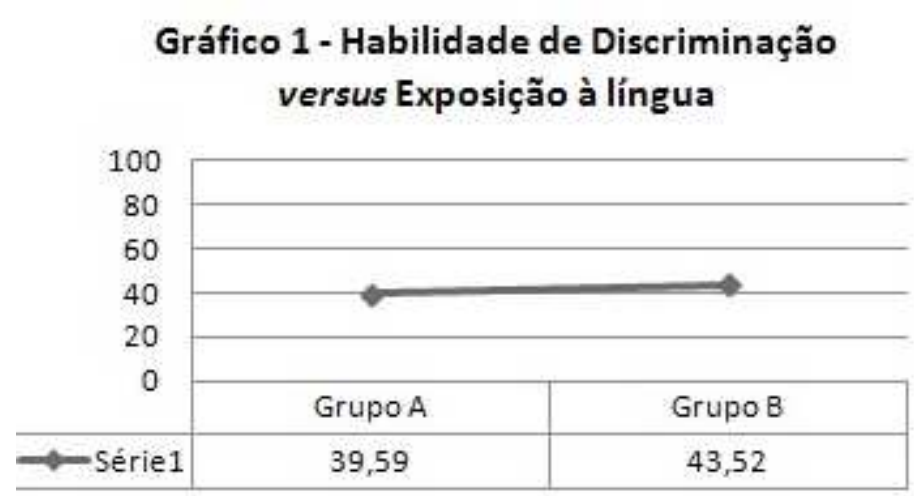

Fonte: Elaboração da autora

Observa-se no gráfico anterior que o grupo B, média de 43,52, apresenta leve favorecimento na habilidade de discriminação em relação ao grupo A, média 39, 59. Essa diferença entre as médias, não obstante, não se mostra significativa $(U=-, 065, p>0,05)$, indicando não haver influência da variável no que tange à discriminação do contraste. O mesmo agrupamento foi realizado para a tarefa de identificação de / $/$ / e identificação de /1/, conforme observa-se nos Gráficos 2 e 3, com a apresentação da média percentual de cada grupo.

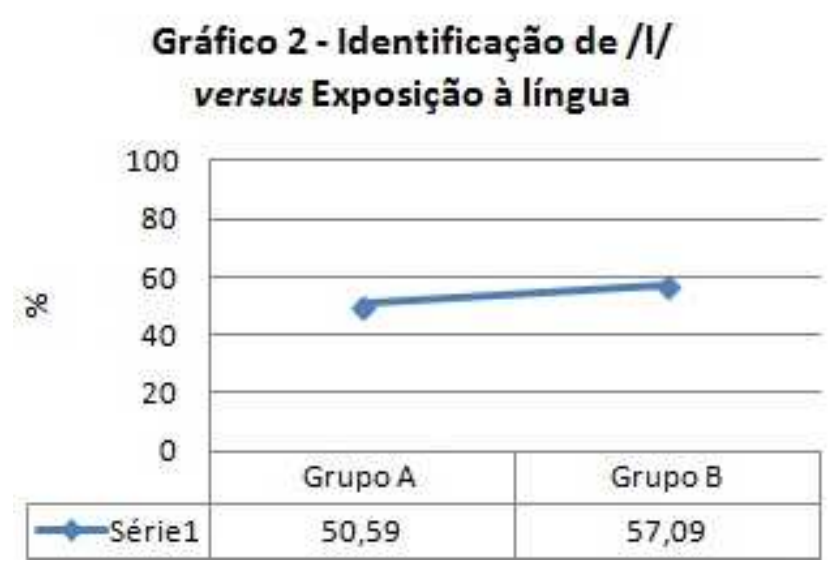

\section{Gráfico 3 - Identificação de /r/ versus Exposição à língua}

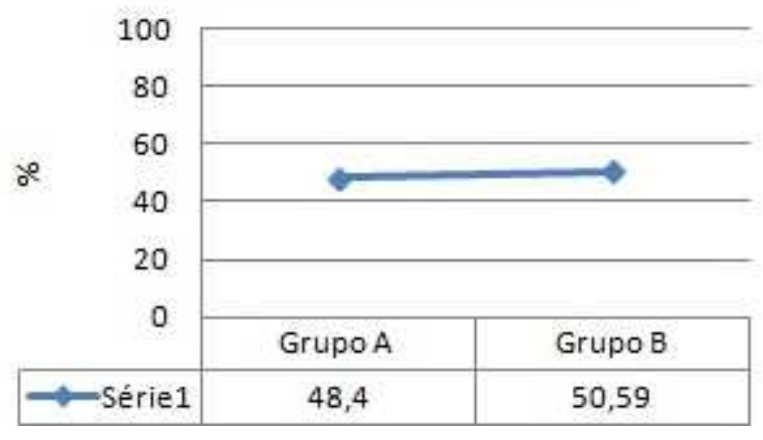

Fonte: Elaboração da autora

Os resultados expressos nos Gráficos 2 e 3 revelam que o grupo B, com maior tempo de exposição à língua, tende a apresentar melhor desempenho na identificação dos dois segmentos, /l/ e / $/$ /. A diferença entre as médias mostra-se mais saliente na identificação de /1/, 57,09 para o Grupo B e 50,59 para o Grupo A, com diferença significativa $(U=, 258, p=0,050)$. Na identificação de / $\mathrm{r} /$ a diferença entre as médias, 50,59 para o Grupo B e 48,4 para o Grupo A, não se mostra significativa $(U=-, 326, p>0,05)$.

Diante dos resultados, não se pode confirmar o efeito positivo e uniforme da exposição à língua nas habilidades de discriminação e identificação, contrariando as hipóteses previstas inicialmente. Salienta-se que o não efeito da variável no grupo, nesse caso considerando a divisão realizada, pode estar relacionado à própria particularidade desses imigrantes e, também, à forma como a variável foi estruturada nas atividades contempladas e a possíveis generalizações de respostas. ${ }^{7}$ Rei- 
tera-se, ainda, como discutido na parte introdutória, que os imigrantes haitianos representam ser um grupo peculiar em relação a outros grupos não nativos. Há, nesse caso, necessidade de olhar para aspectos outros, individuais, que possam estar influenciando no comportamento. Julgou-se, por conseguinte, pertinente levantar outros aspectos, tais como o tempo em que informantes estão frequentando curso de português no Brasil e também a condição em que residem no país.

$\mathrm{Na}$ avaliação da variável curso, considerou-se o tempo, em meses, que o informante está frequentando curso de português. Ressalta-se que todos os participantes estavam, no momento da pesquisa, participando de cursos, sendo alguns iniciantes e outros com maior tempo, sem, no entanto, haver treinamento específico para a percepção e pronúncia de sons. A Tabela 2, a seguir, apresenta os resultados da correlação entre tempo de curso e o desempenho nas tarefas de discriminação e identificação.

Tabela 2 - Tempo de Curso versus Habilidades de Discriminação e Identificação

\begin{tabular}{lll}
\hline Tarefa & Resultado do teste & Significância \\
\hline Discriminação & $\left(\mathrm{r}_{\mathrm{s}}=+0,30\right)$ & $\mathbf{p}=\mathbf{0 , 0 2 6}$ \\
Identificação $/ \mathrm{l} /$ & $(\mathrm{r}=+0,26)$ & $\mathrm{p}=0,297$ \\
Identificação $/ \mathrm{r} /$ & $(\mathrm{r}=+0,46)$ & $\mathbf{p}=\mathbf{0 , 0 0 3}$
\end{tabular}

Fonte: Elaboração da autora

Os resultados revelam haver uma correlação positiva entre tempo de curso e o desempenho nas tarefas de discriminação e identificação. Observa-se, nesse sentido, a tendência a um aumento na habilidade de percepção, na medida em que há o aumento do tempo de curso. Essa correlação entre desempenho e tempo de curso apresenta-se significativa para a tarefa de discriminação e para a tarefa de identificação para o segmento $/ \mathrm{r} /$. As evidências, portanto, apontam para um papel positivo da variável tempo de curso, o que está em conformidade com as hipóteses previstas, tendo em conta que aqueles que estão frequentando curso, embora não diretamente com o treinamento específico dos aspectos fonético-fonológicos, possuem tempo maior de instrução explícita à língua. Seguindo a concepção de Alves
(2004) e Alves; Zimmer (2005), a instrução explícita é tomada aqui em um sentido mais amplo, estando relacionada às possibilidades que o informante encontra de usar a língua no contexto formal de sala de aula.

Informantes que possuem acesso à instrução explícita formal, além de terem a oportunidade de interagir no idioma não nativo, não somente com seus pares, mas também com outros estrangeiros e nativos da língua alvo, professores e monitores, recebem maior quantidade de input e também um feedback de sua fala, compreensão e escrita. No caso dos informantes haitianos, pelas características inerentes ao grupo, em que há contato mais próximo entre seus pares e, consequentemente, a comunicação cotidiana ocorre, na maior parte do tempo, em crioulo haitiano, o acesso à instrução explícita em sala de aula torna-se ainda mais significativo. Entende-se que o espaço da aula é uma forma de socialização com o uso predominante da língua portuguesa, além de proporcionar o acesso ao texto escrito, que muitos não possuem, e também propiciar o acesso a diferentes usos da língua na mídia: vídeos, músicas, entre outros, não corriqueiros e familiares para todos os haitianos.

Além do tempo de curso, foram levantadas questões relacionadas à condição de moradia dos informantes no Brasil, mais diretamente quanto ao convívio cotidiano com outras pessoas. As opções, nesse caso, eram relativas aos possíveis companheiros com quem o informante reside no Brasil, isto é, se com amigos brasileiros, com amigos de seu país, com família haitiana, família brasileira, ou mesmo, sozinho. Pelas condições com que os haitianos vieram ao Brasil, ocorrendo na maioria dos casos a vinda de apenas um membro do grupo familiar, muitos deles, pelo menos no início de seu processo migratório, vieram a residir com os próprios colegas, situação que, com o tempo, tende a se modificar, com a oportunidade de trazer outras pessoas da família, ou mesmo de passar a conviver com brasileiros, criando laços de amizade. Não se mostra muito frequente, mesmo com o passar do tempo, haitianos constituírem família com brasileiros, e raros são os casos em há divisão de espaço com amigos brasileiros.

Dos fatores controlados, apenas dois foram preenchidos pelos informantes deste estudo, possibilitando a 
formação de apenas dois grupos ${ }^{8}$ : (i) - informantes que residem com colegas amigos/haitianos (08 integrantes); (ii) - informantes que residem com família haitiana (5 integrantes). O desempenho desses informantes na tarefa de discriminação é apresentado no Gráfico 4.

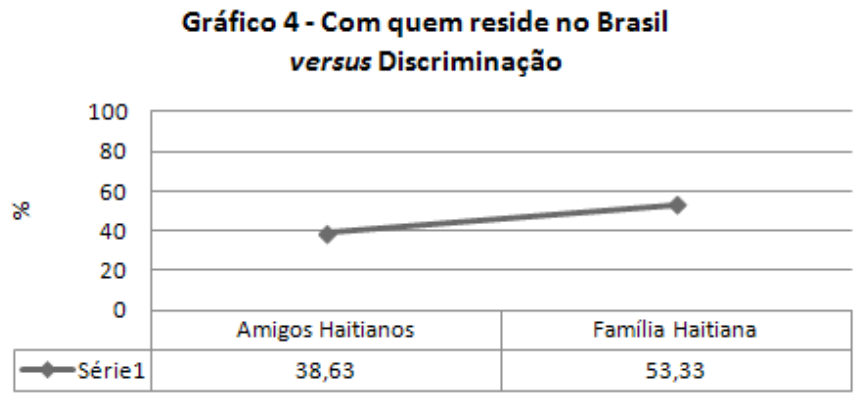

Fonte: Elaboração da autora

Observa-se um melhor desempenho do grupo de informantes que reside com família haitiana, média de 53,33 , em relação ao grupo que reside com amigos haitianos, 38,63. Tais resultados, com diferença comprova$\mathrm{da}(\mathrm{t}(11)=, 899, \mathrm{p}<0,05)$, demonstram que o fato de $\mathrm{o}$ informante residir no Brasil com sua família tem uma influência positiva em seu processo de aquisição da língua não nativa. Comportamento semelhante é observado no papel da variável para os testes de identificação, mais precisamente na identificação de / $/$, representados nos Gráficos 5 e 6.

\section{Gráfico 5 - Com quem reside no Brasil versus Identificação/I/}

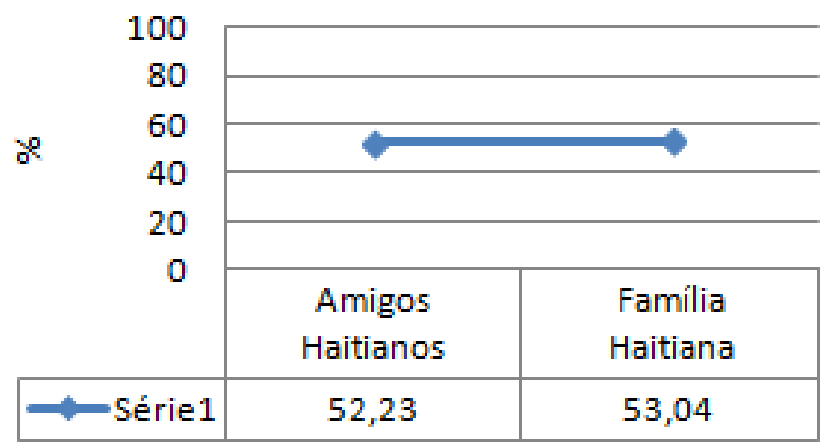

Fonte: Elaboração da autora

De acordo com os resultados, no que se refere à identificação do segmento /1/, os dois grupos apresentam comportamento semelhante, média de 52,23 para o grupo que reside com amigos haitianos e de 53,04 para o grupo que reside com família haitiana, sem diferença significativa $(t(11)=0,883, p>0,05)$ entre as médias. Observa-se, não obstante, uma diferença marginalmente significativa dos grupos na identificação de $/ r /$, com uma média de 43,08 para o grupo que reside com amigos haitianos e, de 54,46, para o grupo que reside com família haitiana $(\mathrm{t}(11)=0,462, \mathrm{p}=0,067)$.

O papel favorável da variável, com indicação positiva para o fato de o informante residir no Brasil com sua família, sugere-se estar relacionado a outras questões, como maior identificação com o país e, consequentemente, atitudes positivas perante o idioma. Muitos dos imigrantes haitianos que ainda tem sua família no Haiti, pensam em retornar ao seu país e acabam, mesmo de que forma inconsciente, não apresentando motivação suficiente para a aprendizagem do idioma. Por outro lado, aqueles informantes que estão aqui com suas famílias mostram o desejo de permanecer no país e, por tal razão, apresentam atitude mais positiva frente ao idioma. O tempo de uso do idioma português em casa também se tem por hipótese de que seja maior para o grupo que reside com a família, uma vez que muitos desses informantes relatam falar português em casa com os filhos e sentem essa necessidade para tentar aprender o idioma e se inserir nos espaços sociais.

A partir das análises até aqui apresentadas e frente ao fato de não ser possível apontar, a partir do desempenho

\section{Gráfico 6 - Com quem reside no Brasil versus Identificação/r/}

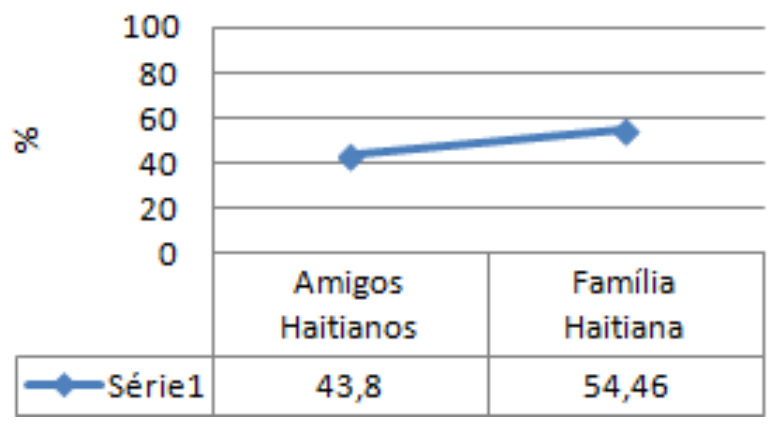

do grupo como um todo, fatores que mais diretamente poderiam estar respondendo por diferenças de comportamento, pelo menos não de forma uniforme, optou-se por realizar ainda uma observação de cada informante. A proposta permite visualizar de maneira mais transparente 
a relação do perfil do participante com o desempenho nas tarefas. Possíveis diferenças de comportamento entre indivíduos no processo de aquisição são esperadas, uma vez que se entende, de acordo com Best e Tyler (2007), que se trata de um processo individual e que depende tanto de fatores relacionados aos anos de residência quanto aos fatores relacionados à exposição. Pela especificidade e características do grupo de haitianos que compõem o corpus de estudo, essa hipótese se reforça, pelo entendimento da forma como esses imigrantes chegaram ao Brasil, das suas características individuais e dos fatores sociais que permeiam suas estadas no país.

São expostas no Quadro 2 possíveis características de cada participante, coletadas no questionário de informações sociais, que possam contribuir para a compreensão das diferenças de desempenho nas tarefas propostas por este estudo. Procurou-se seguir as mesmas variáveis verificadas estatisticamente no grupo, apontando, a partir destas, o perfil e o desempenho individual de cada participante.

Quadro 2 - Perfil dos informantes versus desempenho
Observa-se nos resultados descritos na tabela, conforme esperado, uma visível heterogeneidade dos integrantes do grupo quanto ao perfil e ao desempenho logrado nas tarefas de percepção, AX e identificação. Com melhor desempenho em ambos os testes, pode-se observar os informantes de número 1, 2, e 7, marcados por $\left(^{*}\right)$. Em comum esses informantes possuem tempo de residência igual ou superior a 18 meses, tempo de curso de 12 meses e o fato de residirem no Brasil com família haitiana. Esse resultado sugere haver uma atuação conjunta de fatores que contribuem para a melhora de desempenho desses participantes na dissimilação das categorias fonológicas.

Quanto ao tempo de exposição e uso do português em situações de fala e escuta, revelam ter maior tempo os informantes de número 2 e 7 . Curiosamente, o informante de número 1 , com altos índices de desempenho, assinala ter um tempo de exposição menor ao português; não obstante, a análise de seu perfil social indica que o mesmo frequenta curso de graduação no Brasil e trabalha em uma empresa com atendimento ao público, dados que direcionam para um contato com o

\begin{tabular}{|c|c|c|c|c|c|c|c|c|}
\hline \multirow[t]{2}{*}{$\begin{array}{c}\text { Inform } \\
\text { ante }\end{array}$} & \multirow{2}{*}{$\begin{array}{l}\text { Tempo de } \\
\text { residência } \\
\text { no Brasil }\end{array}$} & \multicolumn{2}{|c|}{$\begin{array}{c}\text { Com quem reside } \\
\text { no Brasil }\end{array}$} & \multirow[t]{2}{*}{$\begin{array}{l}\text { Tempo de } \\
\text { curso }\end{array}$} & \multirow[t]{2}{*}{$\begin{array}{c}\text { Exposição } \\
(\%)\end{array}$} & \multirow[t]{2}{*}{$\begin{array}{l}\text { Pontuação } \\
\text { tarefa AX }\end{array}$} & \multicolumn{2}{|c|}{$\begin{array}{l}\text { Pontuação } \\
\text { Identificação }\end{array}$} \\
\hline & & $\begin{array}{l}\text { Familia } \\
\text { haitiana }\end{array}$ & $\begin{array}{l}\text { Amigos } \\
\text { haitianos }\end{array}$ & & & & I & / \\
\hline $1 *$ & 18 meses & $\mathrm{X}$ & & 12 meses & $40 \%$ & $85 \%$ & $88 \%$ & $76,2 \%$ \\
\hline $2 *$ & 20 meses & $\mathrm{X}$ & & 12 meses & $75 \%$ & $75 \%$ & $73 \%$ & $80 \%$ \\
\hline 3 & 12 meses & $\mathrm{X}$ & & 08 meses & $70 \%$ & $35 \%$ & $66,6 \%$ & $35,7 \%$ \\
\hline $4 * *$ & 16 meses & & $\mathrm{X}$ & 09 meses & $50 \%$ & $30 \%$ & $54 \%$ & $69 \%$ \\
\hline $5 * *$ & 16 meses & $\mathrm{X}$ & & 14 meses & $60 \%$ & $82 \%$ & 69,05 & $33,3 \%$ \\
\hline 6 & 18 meses & & $\mathrm{X}$ & 08 meses & $25 \%$ & $12 \%$ & $66,7 \%$ & $11,9 \%$ \\
\hline 7* & 24 meses & $\mathrm{X}$ & & 12 meses & $90 \%$ & $65,5 \%$ & $52,08 \%$ & $78,6 \%$ \\
\hline 8 & 10 meses & & $\mathrm{X}$ & 06 meses & $35 \%$ & $10 \%$ & $64,3 \%$ & $40,5 \%$ \\
\hline 9 & 04 meses & & $\mathrm{X}$ & 02 meses & $75 \%$ & 27,05 & $45 \%$ & $42,7 \%$ \\
\hline 10 & 18 meses & & $\mathrm{X}$ & 08 meses & $45 \%$ & $17 \%$ & $25 \%$ & $47,6 \%$ \\
\hline 11 & 10 meses & & $\mathrm{X}$ & 06 meses & $30 \%$ & $35 \%$ & $43,8 \%$ & $45,2 \%$ \\
\hline 12 & 04 meses & & $\mathrm{X}$ & 06 meses & $55 \%$ & $27 \%$ & $50 \%$ & $38 \%$ \\
\hline 13 & 10 meses & & $\mathrm{X}$ & 06 meses & $70 \%$ & $30 \%$ & $27,1 \%$ & $59,5 \%$ \\
\hline $14^{* t * t}$ & 14 meses & * & * & 12 meses & $85 \%$ & $62 \%$ & $45,2 \%$ & $54 \%$ \\
\hline
\end{tabular}

*** Informante que revela morar com família brasileira 
português em situações de leitura e fala maior do que o tempo informado em sua autoavaliação.

Nota-se, ainda, um desempenho mediano do informante de número 14 , com média de $62 \%$ na tarefa AX e de $54 \%$ na identificação de $/ r /$. Esse informante, de acordo com sua ficha social, está no Brasil por um tempo de 14 meses, frequenta curso há 12 meses e informou, no momento da pesquisa, estar residindo com família brasileira, por um tempo de 03 meses. Entendese que nesse caso a tendência à melhora de desempenho está relacionada ao fato de o participante residir com brasileiros e ter consequentemente maior tempo de uso da língua nas situações cotidianas, bem como uma relação positiva com o idioma.

No que tange aos demais informantes, observa-se maior dificuldade nos testes, com tendência ainda a não dissociar as categorias de $/ 1 / \mathrm{e} / \mathrm{r} /$. Tal fato se revela nos resultados para o teste de discriminação, no qual, em geral, os informantes tendem a apresentar menores índices em relação à identificação. Ao verificar os dados da tabela para o teste de identificação das categorias /l/ e / $\mathrm{r} /$, faz-se importante observar que as taxas de identificação de $/ 1 /$, segmento presente tanto no português quanto no crioulo, não tendem a ser tão elevadas em grande parte dos casos, o que corrobora, conforme discutido anteriormente, o entendimento de que ainda não há dissimilação das duas categorias, /1/ e /r/ (FLEGE, 1995; BEST; TYLER, 2007). Para haver a dissimilação das duas categorias, o esperado seria o informante apresentar alto índice de identificação em ambos os segmentos, ou seja, sem haver a substituição em nenhum dos casos.

Quanto ao perfil desses informantes com menores pontuações, em comum, se pode observar, com exceção dos informantes de número 3, 6 e 10, um tempo de residência inferior a um ano e o tempo de curso inferior a 8 meses. Exceto o informante de número 03, os demais afirmam residir com amigos haitianos. Os informantes de número 4 e 5 , marcados por $\left.{ }^{* *}\right)$, chamam a atenção por apresentarem pontuações díspares nas tarefas de discriminação e de identificação. O informante de número 5 apresenta pontuação de $85 \%$ na tarefa de discriminação e de apenas 33\% na identificação de / r/. Já o informante de número 4 , apresenta pontuação de $30 \%$ na tarefa de identificação e de $69 \%$ na identificação de $/ \mathrm{r} /$. As diferenças que esses informantes apresentam de acordo com o tipo de teste, por hipótese, podem estar relacionadas à maior dificuldade encontrada para realizar uma ou outra tarefa.

Aspectos em comum a grande parte dos informantes que tendem a apresentar menores índices de pontuação estão relacionados com a rotina de trabalho e práticas sociais cotidianas. Praticamente todos ocupam cargos de trabalho manual, com pouco uso do idioma português e, além do curso que frequentam, não estão engajados em outros grupos sociais em que se use o português, tais como igreja, cursos, treinamentos, entre outros. Embora alguns tenham apontado ter razoável índice de uso e exposição ao português em situações de fala e escuta, as práticas sociais cotidianas e o fato de a convivência prevalecer em grupos de amigos haitianos contribuem para que prevaleça ainda o uso do Crioulo.

\section{Considerações Finais}

O presente estudo buscou verificar a aprendizagem do português como Língua Adicional por imigrantes haitianos, investigando a habilidade de identificar e discriminar o contraste entre as líquidas $/ \mathrm{l} / \mathrm{-} / \mathrm{r} /$, não presente no crioulo haitiano. Com apoio dos pressupostos teóricos voltados para aprendizagem fonológica em L2 (FLEGE, 1995; BEST; TYLER, 2007), a observação empírica por testes de percepção permitiu observar a tendência de os informantes assimilarem os sons da L2 com base em sua língua nativa. Nesse caso, não sendo a consoante $/ \mathrm{r} /$ categorizada como categoria independente de /l/, são recorrentes os casos de não diferenciação de formas contrastivas como caro - calo, para - pala.

Observou-se, não obstante, que o comportamento do grupo não se mostrou uniforme e que há um papel positivo de o informante estar ou não frequentando curso de português no Brasil. As características peculiares do grupo, evidenciadas ao longo do texto, tais como as condições de vinda para o Brasil, as condições de residência, se com a família ou com amigos haitianos, também são fatores que mostram estar relacionados com o desempenho dos participantes na aprendizagem do idioma. As discussões levantadas, embora não de forma 
exaustiva, indicam passos para outras pesquisas com o grupo, incluindo haitianos domiciliados em outras regiões do Brasil, buscando medir, talvez de uma forma mais direta, aspectos individuais, quanto à percepção dos imigrantes sobre o idioma e sobre o país, que se sugere podem influenciar no processo de aquisição.

Reitera-se a importância de pesquisas que se voltem para os diferentes aspectos relacionados com a aquisição do português por imigrantes haitianos. Diferente de outros processos migratórios, as condições vulneráveis do grupo de haitianos apontam para a necessidade de um acolhimento pedagógico diferenciado no ensino/aprendizagem da língua. No âmbito social esses imigrantes, muitas vezes, não desfrutam das mesmas oportunidades de outros grupos, não há facilidade de inserção social e realizam trabalhos manuais, com uso da força física que, por vezes, não demandam a utilização direta do idioma. Com isso, esses imigrantes passam a viver em ilhas, por assim dizer, com seus pares, utilizando como base para a comunicação seu idioma nativo. Temos, portanto, um grupo bastante peculiar e que merece o olhar de nossas pesquisas, de nosso entendimento da língua.

Por fim, embora este trabalho tenha se detido prioritariamente nos aspectos fonético-fonológicos com um grupo pequeno de haitianos, o estudo lança contribuições para a continuidade de outras pesquisas que já estão sendo realizadas com esses imigrantes, incluindo futuramente testes de produção que possam observar se há dificuldade na produção dos segmentos aqui em estudo.

\section{Notes}

1. Neste quesito, faz-se menção ao estudo de Silva (2015) com a proposta de uma ferramenta didática para o ensino do PB para falantes nativos do Crioulo Haitiano, com foco no acento primário das palavras do português.

2. Utilizamos o termo Língua Adicional com base em Santos \& Burgeile (2015), com o entendimento de que os imigrantes haitianos são todos bilíngues e o português é para esses imigrantes segunda, terceira ou quarta língua.

3. Some people may think in error that Creole is simple or primitive compared to a language like French because, say, Creole, does not have verb inflection suffixes for tense, person, and number [tradução nossa].
4. Os fenômenos referentes à supressão de fonemas e à troca na posição do acento não são abordados por este estudo, uma vez que a proposta centra-se na percepção do contraste entre as liquidas /l/ e / $/$.

5. Projeto de pesquisa previamente aprovado pelo Comitê de Ética em Pesquisa da Universidade Tecnológica Federal do Paraná - CAAE - 55244716.3.0000.5547

6. A decisão pela aplicação de testes paramétricos ou não paramétricos neste estudo foi tomada após o teste de normalidade pelos testes Kolmogorov-Sminrnov e Shapiro-Wilk. Em caso de comparação de grupos considerou-se também o teste de homogeneidade das variâncias.

7. A generalização de respostas a que nos referimos está relacionada à possibilidade de o informante responder de forma genérica o número de horas de exposição em cada atividade, sem avaliar e pensar no real tempo em que desenvolve e fica exposto em cada tarefa. Muitas vezes, sua resposta pode ter um caráter muito subjetivo, o que dificulta um levantamento preciso do tempo em cada atividade, gerando apenas uma estimativa.

8. Neste estudo, apenas 01 informante revelou ter família brasileira pelo tempo de 03 meses. O desempenho deste informante foi avaliado separadamente $e$ mostrou percentuais medianos nas tarefas realizadas, entre $50 \%$ e $60 \%$.

\section{Referências}

ALVES, Ubiratã Kickhöfel. O papel da instrução explícita na aquisição fonológica do inglês como L2: evidências fornecidas pela Teoria da Otimidade. Pelotas: Dissertação de Mestrado, UCPel, 2004.

ALVES, Ubiratã Kickhöfel; ZIMMER, Márcia Cristina. A instrução explícita na aprendizagem da L2: uma abordagem conexionista. Nonada: Letras em Revista, Porto Alegre, n. 8, p. 221-232, 2005.

ALTENHOFEN, Cléo Vilson;OLIVEIRA, Gilvan Müller de. $O$ in vitro e o in vivo na política da diversidade linguística do Brasil. In: ALTENHOFEN, Cléo V:;M ELLO, Heliana; RASO, Tommaso (Orgs.). Os contatos linguísticos no Brasil. Belo Horizonte: Editora UFM G, 2011. p. 187-216.

ANTONIOU, Mark; TYLER, Michael; BEST, Catherine. Two ways to listen: do L2-dominant bilinguals perceive stop voicing according to language mode? Journal of phonetics, v. 40, p. 582 - 594, 2012.

AOYAMA, Guion et al. The first years in a L2 speaking environment: a comparison of Japanese children and adults learning American English. International Journal of Applied Linguistics, 46, p.61 - 90, 2008. 
BEST, Catherine; TYLER, Michael. Nonnative and second-language speech perception: commonalities and complementarities. In.: MUNRO, Murray; BOHN, Ocke-Schwen. Language experience in second language speech learning: in honor of James Emil Flege. Amesterdam/ Philadelphia: John Benjamin's Publishing Company, p. 13 - 34, 2007.

BEAUBRUN, Carolyn. Thephonological analysis of bilingual Creole/ English children living in South Florida. Thesis (Master of Science) Florida International University, 2004.

BETTONI-TECHIO, Melissa; RAUBER, Andreia; KOERICH, Rosana. Perception and production of word final alveolar stops by Brazilian Portuguese learners of English. Proceedings of Interspeech, v. 8, p. 2293 - 2296, 2007.

BISOL, Leda. Introdução a estudos de fonologia do português brasileiro. $5^{\mathrm{a}}$ ed.Porto Alegre: EDIPUCRS, 2010.

BONENFANT, Jacques. History of Haitian-Creole: from pidgin to lingua franca and english influence on the language. Review of higher education and selflearning, vol. 4, 2011.

CADELY, Jean-Robert. Les sons du Creòle haïtien. The Journal of Haitian Studies, vol. 9, n.2, p. 4-41, 2004.

CAISSE, Peter Thomas et al. A vitalidade linguística dos crioulos do Haiti e da Luisiana: os limites da política e das atitudes linguísticas. Dissertação (Mestrado)- Programa de Pós-Graduação em Linguística,Universidade Estadual de Campinas, Campinas, 2012.

CRISTÓFARO SILVA, Thaïs. Fonética e Fonologia do Português: roteiro de estudos e guia de exercícios. São Paulo: contexto, 2005.

FERRAZ, Anderlande Pereira. O panorama linguístico brasileiro: a coexistência de línguas minoritárias com o português. Filologia Linguística Portuguesa, n. 9, p. 43-73, 2007.

FLEGE, James Emil. Second language speech learning theory, findings, and problems. In.: STRANGE, Winifred (ed.). Speech perception and linguistic experience: issues in cross language research. Timonium, MD: York Press, 1995.

FLEGE, James Emil; LIU, Serena. The effects of experience on adults acquisition of a second language. Studies in Second Language Acquisition, n. 23. p. 527 -552, 2001.

HATTORI, K; IVERSON, P. Examination of the relantionship between L2 perception and production: an investigation of English /r/ - /l/ perception and production by adult Japonese speakers. In.: Interspeech Workshop on Second Language Studies: Acquisition,
Learning, Education and Technology. ed. Nacano: Waseda University, p. 22-24, 2010.

MARTINS, Maria da Graça. A aquisição da Língua Portuguesa por Imigrantes Haitianos em Porto Velho. Dissertação (Mestrado)- Fundação Universidade Federal de Rondônia, 2013.

MATTOSO CÂMARA, Joaquim Jr. Estrutura da língua portuguesa. $40^{\mathrm{a}}$ ed. Rio de Janeiro: Petropólis, 2009.

MONARETTO, Valéria. Descrição da vibrante no português do sul do Brasil. In.: BISOL, Leda; COLlisCHONN, Gisela (Org.) Português do Sul do Brasil: variação fonológica. Porto Alegre: EDIPUCRS, 2009.

PEPERKAMP, Sharon; BOUCHON, Camillia. The relation between perception and production en L2 phonological processing. Interspeeh, v. 28, n. 31, p. 161-164, 2011.

PIMENTEL, M. Lima; COTINGUIBA, G. Castro; RIBEIRO, A. da Silva. O crioulo haitiano e seu reconhecimento político. Universitas Relações Internacionais, vol. 14, n. 1, jan/junh/2016.

PONSO, Letícia. A variação do português em contato com o italiano na comunidade bilíngue de São Marcos-RS. Dissertação (Mestrado) - Programa de Pós-Graduação em Letras, Universidade Federal do Rio Grande do Sul, Porto Alegre, 2003.

$\mathrm{OH}$, Grace et al. A one-year longitudinal study of english and japanese vowel production by japanese adults and children in an english- speaking setting. Journal of Phonetics, n. 39, p. 2 - 12, 2011.

RAUBER, Andréia Schurt; RATO, Anabela, KLUGE, Denise Cristina; SANTOS, Giane Rodrigues dos. TP: testes de percepção/tarefas de treinamento perceptual [aplicativo]. Disponível em: http://www.worken.com. br/tp, acesso em: 10 de agosto/2016.

RODRIGUES, Luiz Carlos Balga. Frances, crioulo e vodu: a relação entre língua e religião no Haiti. Tese(Doutorado) - Programa de Pós-Graduação em Letras, Universidade Federal do Rio de Janeiro, Rio de Janeiro, 2008.

SANTOS, Ednaldo Tartaglia; BURGEILE, Odete. Estratégias Linguísticas para a Aquisição da Língua Portuguesa por um Grupo de Imigrantes Haitianos. Revista Prolíngua, vol. 10, n. 2, 2015.

SILVA, Adelaide H. Pescatori. Uma ferramenta para o ensino do acento primário do PB para falantes nativos do crioulo haitiano. Organon, vol. 30, n. 58: Porto Alegre, 2015.

SPEARS, Arthur. Introduction: The Haitian Creole language. In.: The Haitian Creole language. Lanham, MD: Lexington Books/ Rowman \& Littlefield, 2010. 
62 Susiele Machry da Silva, Aprendizagem do português por imigrantes paitianos: percepção das ...

STRANGE, Winifred;SHAFER, Valerie. Speech perception in second language learners. In.: EDWARDS, Hansen Jett; ZAMPINI, Mary. Phonology and Second Language Acquisition. Amsterdam: John Benjamins Publishing Company, 2008.

VERNET, Pierre. Techniques D'ecriture du Creole Haitien. Haiti: Le Natal, 1980.

Recebido em: 29/03/2017

Aceito em: 10/07/2017 